\title{
COMPARAÇÃO DA COMPOSIÇÃO CORPORAL E DO NÍVEL DE ATIVIDADE FÍSICA DE ALUNOS DO ENSINO MÉDIO ENTRE UMA ESCOLA PÚBLICA E UMA PARTICULAR DE ITAPEVA-SP
}

\author{
Bruno de Souza Vespasiano,Universidade Metodista de Piracicaba - UNIMEP, \\ Piracicaba, São Paulo - Brasil \\ Andressa Mella, Universidade Metodista de Piracicaba - UNIMEP, Piracicaba, São \\ Paulo-Brasil \\ Maria Imaculada de Lima Montebelo, Universidade Metodista de Piracicaba - UNIMEP, \\ Piracicaba, São Paulo - Brasil \\ Marcelo de Castro Cesar, Universidade Metodista de Piracicaba - UNIMEP, Piracicaba, \\ São Paulo - Brasil
}

\section{RESUMO}

O hábito alimentar inadequado e a diminuição da prática de exercícios físicos culminam para o aumento excessivo de gordura corporal em adolescentes. Este estudo teve como objetivo comparar a composição corporal, os hábitos alimentares, nível de atividade física e nível socioeconômico em adolescentes do ensino médio entre uma escola pública e uma particular do município de Itapeva-SP. Foram avaliados 200 adolescentes entre 15 e 17 anos do sexo masculino e feminino. As alunas da rede particular apresentaram maiores valores de estatura, ingestão de carboidratos e maior concentração nas classes socioeconômicas mais elevadas, e menores valores de índice de massa corporal, dobra cutânea tricipital, ingestão de proteínas e proteínas de alto valor biológico quando comparado com as alunas da escola pública. Os alunos da rede particular apresentaram maiores valores de ingestão de energia (kcal), e maior concentração nas classes socioeconômicas mais elevadas quando comparado com os alunos da escola pública. Cerca de $50 \%$ dos voluntários de ambas as escolas eram irregularmente ativos. Programas que invistam na prevenção de sobrepeso e obesidade, e aumento da prática de atividade física são necessários para promoção da saúde dos escolares adolescentes.

Palavras-Chave: Obesidade; Adolescente; Exercício físico; Educação Física; Alimentação.

\section{COMPARISON OF BODY COMPOSITION AND PHYSICAL ACTIVITY LEVEL OF HIGH SCHOOL STUDENTS BETWEEN A PUBLIC SCHOOL AND A PRIVATE ITAPEVA-SP}

\begin{abstract}
The inadequate food habits and decreased physical exercise to culminate the excessive increase of body fat in adolescents. This study aimed to compare body composition, dietary habits, physical activity and socioeconomic status in high school adolescents from a public school and a special municipality of Itapeva-SP. Evaluated 200 adolescents between 15 and 17 years old male and female. The students at private schools had higher values for height, carbohydrate intake and greater concentration in higher socioeconomic classes, and lower values of body mass index, triceps skin fold thickness, protein intake
\end{abstract}


and protein of high biological value when compared with students public school. Students at private schools had higher values of energy intake (kcal), and greater concentration in higher socioeconomic classes when compared to public school students. About $50 \%$ of the volunteers from both schools were irregularly active. Programs that invest in the prevention of overweight and obesity, and increased physical activity are necessary to promote the health of schoolchildren.

Key-Words: Obesity; Adolescent; Physical Exercise; Physical Education; Feed.

\section{COMPARACIÓN DE LA COMPOSICIÓN Y FISICA NIVEL DE ACTIVIDAD DE LOS ESTUDIANTES DE LA ESCUELA ENTRE UNA ESCUELA PUBLICA Y PRIVADA A ITAPEVA-SP}

\section{RESUMEN}

Los hábitos alimentarios inadecuados y disminuyeron el ejercicio físico para culminar el aumento excesivo de la grasa corporal en adolescentes. Este estudio tuvo como objetivo comparar la composición corporal, los hábitos dietéticos, la actividad física y el nivel socioeconómico de los adolescentes de la escuela secundaria de una escuela pública y un municipio especial de Itapeva-SP. Evaluada 200 adolescentes de entre 15 y 17 años de ambos sexos. Los estudiantes de las escuelas privadas presentaron mayores valores para la altura, la ingesta de hidratos de carbono y una mayor concentración en las clases socioeconómicas más altas, y los valores más bajos de índice de masa corporal, el pliegue del tríceps, la ingesta de proteínas y proteínas de alto valor biológico, en comparación con los estudiantes escuela pública. Los estudiantes de las escuelas privadas presentaron mayores valores de ingesta de energía (kcal), y una mayor concentración en las clases socioeconómicas más altas en comparación con los estudiantes de escuelas públicas. Alrededor del 50\% de los voluntarios de ambas escuelas fueron irregularmente activos. Los programas que se invierten en la prevención del sobrepeso y la obesidad, y el aumento de la actividad física es necesaria para promover la salud de los escolares.

Palabras-Clave: Obesidad; Adolescente; El ejercicio físico; La Educación Física; Alimentos. 


\section{INTRODUÇÃO}

A educação no ensino médio, especialmente a educação física, tem passado por grandes transformações que buscam garantir amplo desenvolvimento qualitativo do aluno ${ }^{1}$. A educação física no âmbito educacional tem participação direta nesse processo e deve contribuir para uma formação autônoma do educando, e diante do exposto, e dentre as várias possibilidades inerentes a essa disciplina, o tema saúde ganha destaque uma vez que são observadas mudanças nos adolescentes no que diz respeito à qualidade de vida e tempo gasto com prática de exercícios físicos. ${ }^{1-2}$

Nahas ${ }^{2}$ aponta grande preocupação com a qualidade de vida, e em países industrializados é observado que a inatividade física é fator crucial para a redução da qualidade de vida provocando mortes precoces. Atrelados a diminuição da atividade física, a obesidade se torna evidente na sociedade moderna.

A obesidade pode ser definida como o acúmulo de gordura excessiva no corpo, é um distúrbio que pode se localizar em diversas regiões do organismo, constatado nos homens aumento de gordura na região central do corpo (andróide) e nas mulheres, aumento de gordura na região periférica do corpo (ginóide). ${ }^{2-6}$ A obesidade é decorrente de vários fatores associados, entre eles diminuição de gasto energético, aumento da utilização de recursos tecnológicos, inatividade física, fatores genéticos, fatores metabólicos e endócrinos, com sérias consequências para a saúde como a síndrome metabólica, alguns tipos de câncer além e problemas cardíacos. ${ }^{3}$

Nos últimos 25 anos, a obesidade cresceu tanto nos países desenvolvidos quanto nos países em desenvolvimento. ${ }^{3}$ Com isso, essa epidemia acarreta graves transtornos na saúde e promove grande impacto na qualidade de vida de toda a sociedade.

Observa-se que crianças e adolescentes que tendem a ficar mais tempo em frente à televisão além do uso excessivo do computador diminuem o tempo gasto com exercício físico e consequientemente diminuem gasto energético, expondo-os aos malefícios causados pela obesidade. ${ }^{6}$ 
Diante desses fatos, a obesidade deixa de ser um problema particular, e se torna problema de saúde pública atingindo também, crianças e adolescentes. ${ }^{7-8}$

De acordo com o Instituto Brasileiro de Geografia e Estatística (IBGE) ${ }^{8}$ os resultados encontrados em crianças e adolescentes em relação à obesidade não mudam muito quando comparados com adultos, fato esse devido à transição nutricional que ocorreu nas últimas três décadas, ou seja, o Brasil passou de um quadro de desnutrição para um quadro de maior oferta de alimentos o que favorece o acúmulo de gordura corporal excessivo em crianças e adolescentes. Dessa forma, a obesidade tornou-se um problema crescente na faixa etária infanto-juvenil.

As tendências a obesidade na infância e adolescência são observadas também em várias outras localizações como América do Norte, América Latina e América do Sul, reportando a importância de pesquisar esse assunto. ${ }^{9}$ No Brasil $10 \%$ das crianças até a fase pré-púbere já é considerada obesa, e entre os adolescentes se aproxima a 16\%, destacando que crianças e adolescentes obesos se não tomado providencias necessárias, tendem a se tornarem adultos obesos acarretando impacto negativo na saúde. ${ }^{10-11}$

De acordo com Oliveira et al., ${ }^{9}$ o sobrepeso e a obesidade atingem mais de $20 \%$ de crianças e adolescentes em algumas cidades do Brasil, fato esse que justifica modificações nos hábitos de vida que culminem em melhora da qualidade de vida dessa população. Dentre os componentes de políticas públicas para uma vida saudável em adolescentes, o incentivo de hábitos alimentares saudáveis e implantação de programas de exercícios físicos são fundamentais para a promoção da saúde, e o professor de educação física tem grande destaque nessa área de atuação., 2,9

O professor de educação física atualmente está inserido na área da saúde, na qual, tem entre suas responsabilidades, a de prevenir, orientar e supervisionar a prática correta de exercícios físicos e hábitos de vida saudáveis. ${ }^{2-5,12-13}$

Em estudo realizado em creches e pré-escolas no município de Piracicaba, os resultados obtidos revelaram a existência de um número excessivo de crianças obesas e desnutridas, 
apontando a necessidade de medidas para melhor adequação da alimentação e estímulo à prática de atividade física das crianças. ${ }^{14}$

O espaço escolar que é destinado à formação de cidadãos críticos tem a possibilidade através do professor de educação física, oferecer aos alunos trabalhos de conscientização, onde eles aprenderão que a adoção de um estilo de vida saudável, colabora diretamente para a diminuição da obesidade, ressaltando a idéia que a prevenção nas idades iniciais irá acarretar menores prejuízos com saúde na fase adulta. ${ }^{1,15}$ Vale destacar que, para o professor de educação física desenvolver bom trabalho nessa linha de pensamento, deve considerar vários fatores que interferem diretamente nesse processo como exemplo, as condições sociais, culturais e econômicas de cada localidade.

Desta forma, o professor de educação física é elemento importante de uma equipe multidisciplinar, seja na área da saúde ou no ambiente escolar, e deve integrar a equipe para tratamento de pessoas com doenças crônico-degenerativas. ${ }^{16-18}$

Fundamenta-se então, a importância do professor de educação física trabalhar na prevenção e diminuição da obesidade em escolares. Seabra et al., ${ }^{19}$ reforçam que a instalação de programas de intervenção que sejam motivadores e indutores no sucesso da alteração do estilo de vida dos adolescentes fundamentalmente relacionados com as condições demográficas, biológicas e sócio cultural de cada região, dessa forma os programas de intervenções tendem a ser gratificantes pois, medidas de prevenção podem ser tomadas, devido às alterações positivas que favorecem a prática de atividades físicas. ${ }^{20}$

No entanto, diferenças na prevalência de doenças crônicas nas diversas regiões do Brasil fundamentam a investigação das características de escolares em um município pequeno do interior do Estado de São Paulo. ${ }^{20}$

Como existem grandes desigualdades socioculturais e econômicas entre alunos de escolas particulares e públicas, justifica-se um estudo comparando estudantes destas escolas. ${ }^{20}$

O aumento da cultura sedentária, com diminuição da prática de atividade física e hábitos alimentares inadequados, fortalece o objetivo do presente estudo que teve como proposta Conexões: revista da Faculdade de Educação Física da UNICAMP, Campinas, v. 11, n. 2, p. 31-59, abr./jun. 2013.35 ISSN: 1983-9030 
comparar a composição corporal, hábitos alimentares, nível de atividade física e níveis socioeconômicos em adolescentes de 15 a 17 anos regularmente matriculados do ensino médio, investigando uma escola da rede pública e uma da rede particular do município de Itapeva-SP.

\section{METODOLOGIA}

Este projeto tratou-se de uma pesquisa observacional de corte transversal, realizada no município de Itapeva, localizado no interior do Estado de São Paulo, região sul do estado, que possui 87.753 habitantes. Na cidade há 4.549 alunos matriculados no ensino médio, sendo 4.200 alunos matriculados na rede pública de ensino, distribuídos em 11 unidades escolares e 349 alunos matriculados na rede particular de ensino, distribuídos em cinco unidades escolares.

A amostra deste estudo foi de 200 voluntários, de 15 a 17 anos, regularmente matriculados no ano letivo de 2011, sendo que 100 estavam matriculados na Escola Estadual Zulmira de Oliveira, desse grupo de voluntários $50 \%$ foram do gênero masculino e 50\% foram do gênero feminino e 100 voluntários matriculados no Colégio Objetivo de Itapeva sendo $50 \%$ do gênero masculino e 50\% do gênero feminino. A seleção dos voluntários consistiu em entrevista realizada nas próprias escolas e após a explicação do projeto, os responsáveis pelos voluntários assinaram um termo de consentimento livre e esclarecido. Em nenhum momento os dados individuais coletados foram expostos, sendo utilizados apenas na pesquisa.

Os critérios de exclusão foram: alunos ausentes no dia da coleta de dados e cujos responsáveis não autorizaram a participação no projeto.

Para avaliação investigação do estado de saúde foi utilizado um questionário com intuito de identificar queixas, doenças preexistentes, antecedentes pessoais e familiares, e hábitos de vida.

Para avaliação do nível de atividade física foi utilizado os níveis de classificação de acordo com o IPAQ - versão curta (International Physical Activity Questionaire) validado para

Conexões: revista da Faculdade de Educação Física da UNICAMP, Campinas, v. 11, n. 2, p. 31-59, abr./jun. 2013.36 ISSN: 1983-9030 
estudos em crianças e adolescentes. Posteriormente foi explicado aos voluntários à forma de como responder o mesmo, a fim de auxiliá-los durante a coleta de dados. ${ }^{21-22}$

Para avaliação dos hábitos alimentares foi utilizado o registro alimentar de três dias. ${ }^{23}$ Os alunos preencheram o questionário em casa quais foram os alimentos e qual a quantidade ingerida, em três dias diferentes, sendo, um dia no final de semana (sábado ou domingo) e dois dias no decorrer da semana (segunda-feira a sexta-feira). ${ }^{23}$ Para os cálculos foi utilizada a média dos três registros, sendo determinados os valores dos macronutrientes carboidratos, lipídios, proteínas e proteínas de alto valor biológico. Utilizou-se o software Nutwin (programa de apoio à nutrição) versão 1.6 de 2009 fornecido pela Universidade Federal de São Paulo-UNIFESP.

Para a classificação econômica, foi aplicado o Critério de Classificação Econômica Brasil (CCEB) da Associação Brasileira de Empresas de Pesquisa (ABEP), que divide os grupos populacionais em classes $\mathrm{A}^{1}, \mathrm{~A}^{2}, \mathrm{~B}^{1}, \mathrm{~B}^{2}, \mathrm{C}, \mathrm{D}$ e E. ${ }^{24}$ Cada aluno recebeu um questionário que foi respondido por um responsável e levado de volta no dia solicitado pelo avaliador.

Foram medidas a massa corporal e estatura dos voluntários por meio de uma balança analógica atestada pelo Inmetro da marca Filizola ${ }^{\circledR}$ e um estadiomêtro acoplado à balança precisão de $0,1 \mathrm{~cm}$. Os alunos foram pesados em uma única medição, em pé na balança com as costas retas de frente para o medidor da balança. As pernas e os calcanhares ficaram unidos, braços ao longo do corpo e olhando para frente. Os mesmos estavam descalços e com roupas leves para não afetar a mensuração da massa corporal. Para a aferição da estatura, os escolares estavam em pé, descalços, com os calcanhares unidos, costas retas e com os braços estendidos ao longo do corpo e olhando para frente. ${ }^{25}$

O índice de massa corporal foi calculado dividindo a massa corporal em quilogramas pela estatura em metro elevada ao quadrado. A classificação do índice de massa corporal foi realizada quatro estratos: baixo peso, normal, sobrepeso e obesidade. ${ }^{26-27}$

Foi medida a espessura da dobra cutânea tricipital (DCT). Foram coletadas três medidas de ponto anatômico pré-estabelecido no lado direito do corpo, para registro de valor médio. As medidas foram realizadas com um adipômetro científico da marca Lange ${ }^{\circledR}$. Foram Conexões: revista da Faculdade de Educação Física da UNICAMP, Campinas, v. 11, n. 2, p. 31-59, abr./jun. 2013.37 ISSN: 1983-9030 
considerados normais valores até o percentil 90 e aumentado acima do percentil $90^{15}$ de acordo com a classificação de Frisancho. ${ }^{28}$

Para a análise estatística foi utilizado o software Statistical Package for the Social Sciences (SPSS) versão 17.0. Para os dados quantitativos foi utilizado o teste de Mann-Whitney e para os dados qualitativos o teste qui-quadrado. Para nível de significância foi adotado $P \leq$ 0,05 .

\section{RESULTADOS}

No questionário de avaliação da saúde, as voluntárias do gênero feminino não relataram doenças preexistentes como diabetes, dislipidemia e hipertensão, todas apresentavam ciclo menstrual regular, na escola particular e pública.

A idade das alunas da escola particular foi 15,56 \pm 2,13 anos e da escola pública foi 15,30 $\pm 0,51$ anos, não havendo diferença significante $(P>0,05)$.

As alunas não apresentaram diferenças significantes $(P>0,05)$ para seguintes as variáveis quantitativas: idade, massa corporal, ingestão energética e de lipídios. As alunas da rede particular apresentaram maiores valores de estatura e de ingestão de carboidratos, e menores valores de índice de massa corporal, dobra cutânea tricipital e ingestão de proteínas e proteínas de alto valor biológico (TABELA 1, 2).

Tabela 1 - Média, desvio padrão e análise estatística das variáveis antropométricas das voluntárias do sexo feminino

\begin{tabular}{lcc}
\hline Variáveis & Particular $(\mathbf{n}=\mathbf{5 0})$ & Pública $(\mathbf{n}=\mathbf{5 0})$ \\
\hline Massa corporal $(\mathbf{k g})$ & $54,61 \pm 6,82$ & $58,42 \pm 11,86$ \\
Estatura $(\mathbf{m})$ & $1,64 \pm 0,06 * *$ & $1,58 \pm 0,06$ \\
IMC $\left(\mathbf{k g} / \mathbf{m}^{2}\right)$ & $20,32 \pm 2,55$ & $23,03 \pm 4,09 * *$ \\
DCT $(\mathbf{m m})$ & $22,77 \pm 5,38$ & $29,17 \pm 7,63 * *$ \\
\hline IMC - índice de massa corporal; DCT - dobra cutânea triciptal; kg - quilograma; $\mathrm{m}-$ metro; \\
$\mathrm{kg} / \mathrm{m}^{2}-$ quilograma por metro quadrado; $\mathrm{cm}-$ centímetro; mm - milímetro; \% - percentual. $* P$ \\
$\leq 0,05, * * P \leq 0,01$.
\end{tabular}

Conexões: revista da Faculdade de Educação Física da UNICAMP, Campinas, v. 11, n. 2, p. 31-59, abr./jun. 2013.38 ISSN: 1983-9030 
Tabela 2 - Média, desvio padrão e análise estatística das variáveis da ingestão alimentar diária das voluntárias do sexo feminino

\begin{tabular}{lcc}
\hline Variáveis & Particular $(\mathbf{n}=\mathbf{5 0})$ & Pública $(\mathbf{n}=\mathbf{5 0})$ \\
\hline Energia $(\mathbf{k c a l})$ & $1961,87 \pm 528,03$ & $2097,00 \pm 557,42$ \\
Energia $(\mathbf{k c a l} / \mathbf{k g})$ & $36,50 \pm 10,66$ & $37,45 \pm 12,81$ \\
Carboidratos $(\%)$ & $57,40 \pm 8,80^{* *}$ & $52,38 \pm 8,10$ \\
Lipídios (\%) & $22,54 \pm 6,08$ & $24,01 \pm 5,51$ \\
Proteínas (g/kg) & $1,84 \pm 0,64$ & $2,34 \pm 1,02 * *$ \\
Proteínas AVB (g/kg) & $0,86 \pm 0,50$ & $1,27 \pm 0,71^{* *}$ \\
\hline
\end{tabular}

Kcal - quilocalorias; $\mathrm{kcal} / \mathrm{kg}$ - quilocalorias por quilograma; $\mathrm{g}$ - gramas; alto valor biológico. $* * P \leq 0,01$.

Em relação às variáveis qualitativas, houve diferenças significantes para classificação do índice de massa corporal $(P \leq 0,01)$, da dobra cutânea tricipital $(p \leq 0,01)$ e classe socioeconômica $(P \leq 0,01)$. Não houve diferença significante para o nível de atividade física $(P>0,05)($ FIGURAS $1,2,3,4,5)$.

No índice de massa corporal, as voluntárias da escola particular tiveram maior ocorrência na classificação baixo do peso, não houve diferença significante na classificação normal e as voluntárias da escola pública tiveram maior ocorrência de sobrepeso e obesidade. $\mathrm{Na}$ escola particular, os valores foram: baixo do peso $20 \%$, normal $68 \%$ e sobrepeso $12 \%$. As voluntárias da escola particular não apresentaram valores aumentados para dobra cutânea tricipital, ou seja, todas as alunas estavam na classificação normal.

Nas alunas da escola pública não foram encontradas na classificação com baixo peso, e nas demais os valores percentuais foram: normal $60 \%$, sobrepeso $30 \%$ e obesidade $10 \%$. Sendo que, $24 \%$ das voluntárias da escola pública apresentaram valores aumentados para dobra cutânea tricipital e $76 \%$ estavam na classificação normal.

Na classificação socioeconômica, houve uma concentração das voluntárias nas classes $\mathrm{A}^{1}$ a $\mathrm{B}^{2}$ na escola particular e $\mathrm{B}^{1}$ a $\mathrm{C}^{2}$ na escola pública. 


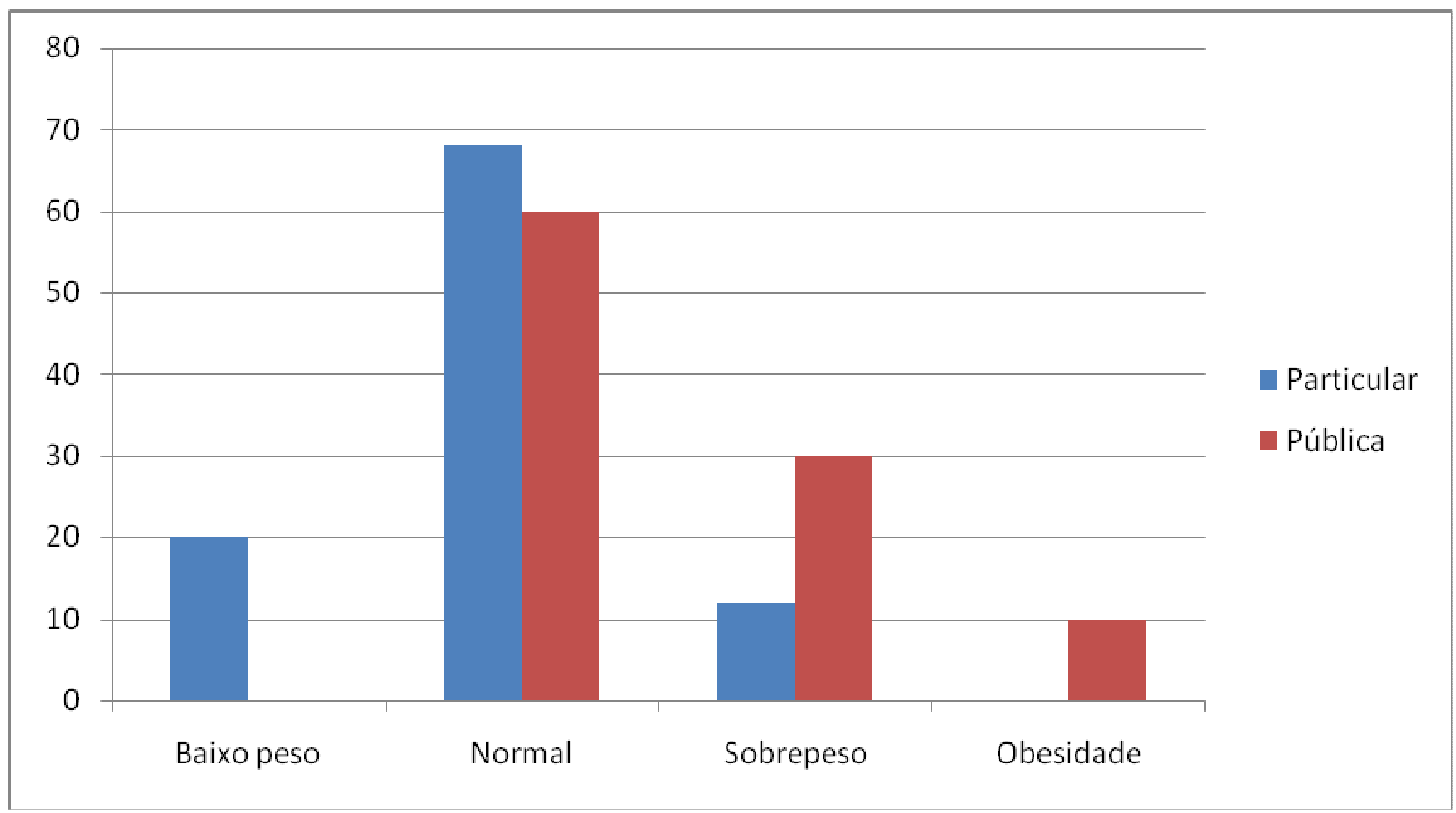

Figura 1: Distribuição percentual dos escolares do sexo feminino segundo a natureza da escola e a classificação do índice de massa corporal. $\quad \mathrm{X}^{2}=19,11 ; P \leq 0,01$.

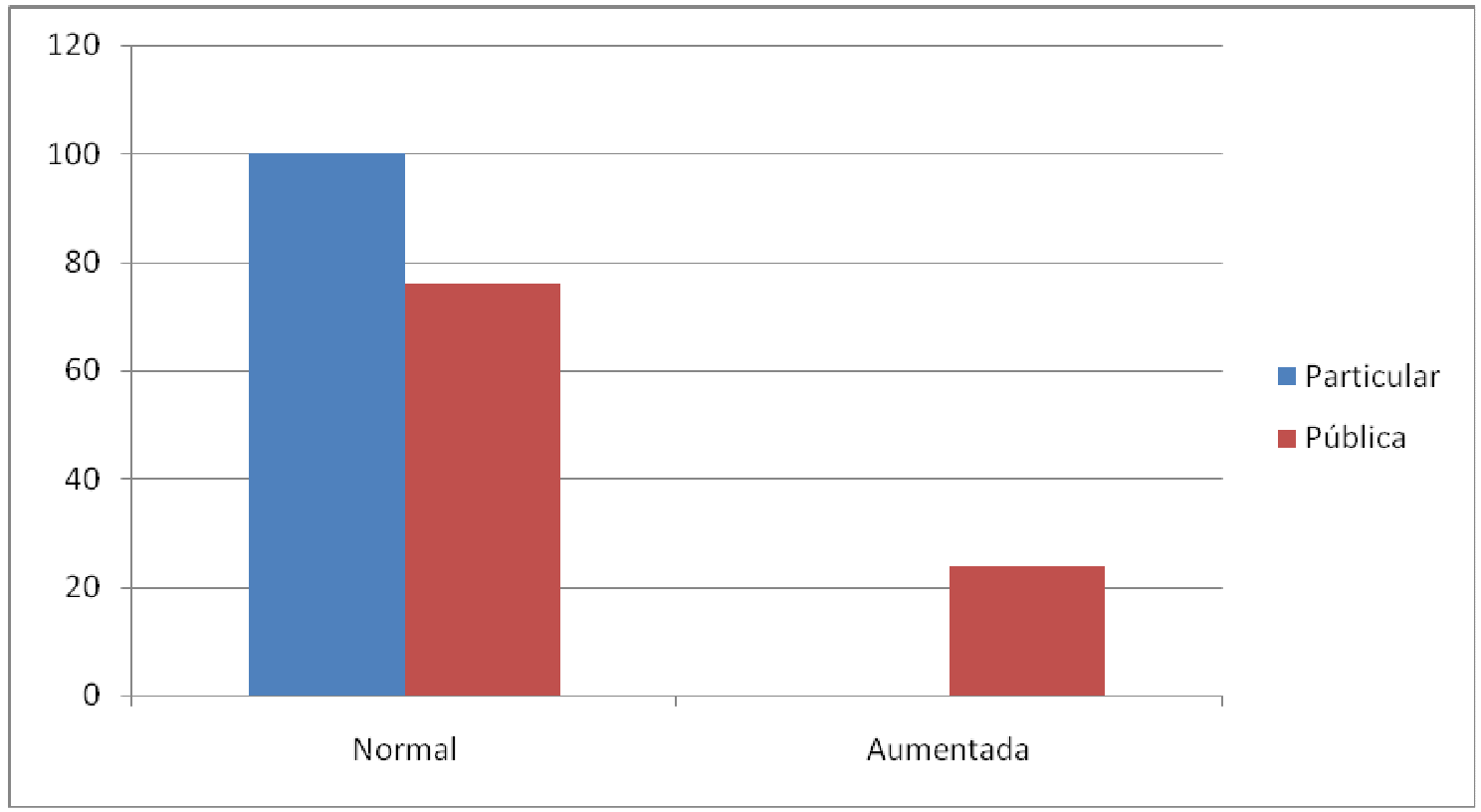

Figura 2: Distribuição percentual dos escolares do sexo feminino segundo a natureza da escola e a classificação da dobra cutânea tricipital. $\mathrm{X}^{2}=13,63 ; P \leq 0,01$. 


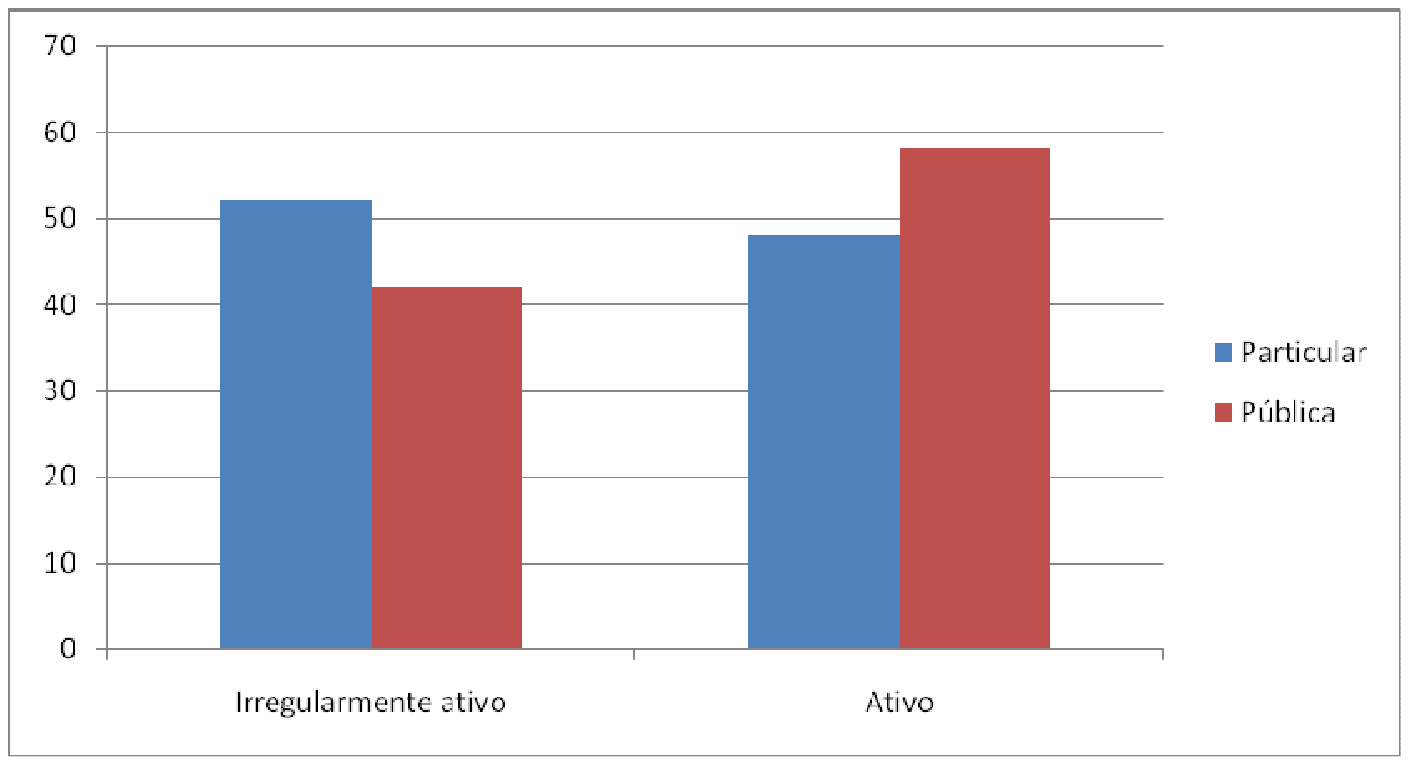

Figura 3: Distribuição percentual dos escolares do sexo feminino segundo a natureza da escola e a classificação do nível de atividade física. $\mathrm{X}^{2}=1,0 ; P=0,32$.

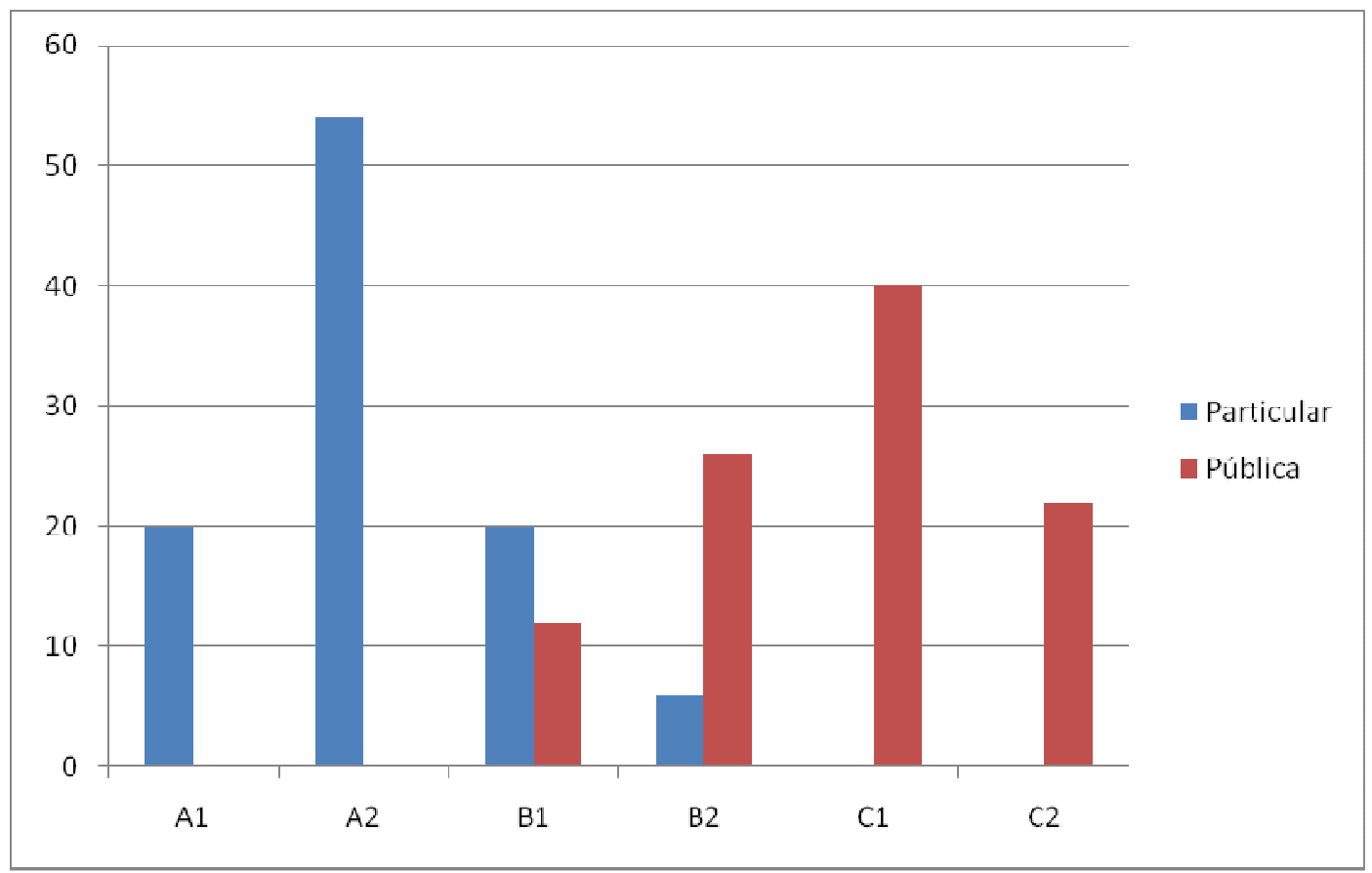

Figura 4: Distribuição percentual dos escolares do sexo feminino segundo a natureza da escola e a classificação socioeconômica. $X^{2}=74,59 ; P \leq 0,01$.

No questionário de avaliação da saúde, os voluntários do gênero masculino não relataram doenças preexistentes como diabetes, dislipidemia e hipertensão, na escola particular e pública.

Conexões: revista da Faculdade de Educação Física da UNICAMP, Campinas, v. 11, n. 2, p. 31-59, abr./jun. 2013. 
A idade dos alunos da escola particular foi $15,40 \pm 0,61$ anos e da escola pública foi 15,20 $\pm 0,45$ anos, não havendo diferença significante $(P>0,05)$.

Os alunos não apresentaram diferenças significantes $(P>0,05)$ para seguintes as variáveis quantitativas: idade, massa corporal, estatura, índice de massa corporal, dobra cutânea tricipital e ingestão de energia $(\mathrm{kcal} / \mathrm{kg})$, carboidratos, lipídios, proteínas e proteínas de alto valor biológico. Os alunos da rede particular apresentaram maiores valores de ingestão de energia em quilocalorias (TABELAS 3, 4).

Tabela 3 - Média, desvio padrão e análise estatística das variáveis antropométricas dos voluntários do sexo masculino

\begin{tabular}{lcc}
\hline Variáveis & Particular $(\mathbf{n}=\mathbf{5 0})$ & Pública $(\mathbf{n}=\mathbf{5 0})$ \\
\hline Massa corporal $(\mathbf{K g})$ & $64,91 \pm 14,30$ & $62,14 \pm 11,13$ \\
Estatura $(\mathbf{m})$ & $1,70 \pm 0,09$ & $1,70 \pm 0,06$ \\
IMC $\left(\mathbf{K g} / \mathbf{m}^{\mathbf{2}}\right)$ & $22,20 \pm 3,62$ & $21,54 \pm 3,14$ \\
DCT $(\mathbf{m m})$ & $21,82 \pm 6,38$ & $21,11 \pm 7,24$
\end{tabular}

IMC - índice de massa corporal; DCT - dobra cutânea triciptal; kg - quilograma; $\mathrm{m}$ - metro; $\mathrm{kg} / \mathrm{m}^{2}$ - quilograma por metro quadrado; $\mathrm{cm}$ - centímetro; $\mathrm{mm}$ - milímetro; \% - percentual.

Tabela 4 - Média, desvio padrão e análise estatística das variáveis da ingestão alimentar diária dos voluntários do sexo masculino

\begin{tabular}{lcc}
\hline Variáveis & Particular $(\mathbf{n}=\mathbf{5 0})$ & Pública $(\mathbf{n}=\mathbf{5 0})$ \\
\hline Energia $(\mathbf{k c a l})$ & $2121,78 \pm 455,63 * *$ & $1903,22 \pm 327,32$ \\
Energia $(\mathbf{k c a l} / \mathbf{k g})$ & $33,94 \pm 9,19$ & $31,64 \pm 8,02$ \\
Carboidratos $(\%)$ & $51,66 \pm 8,16$ & $53,21 \pm 7,73$ \\
Lipídios $(\%)$ & $24,99 \pm 5,49$ & $23,60 \pm 4,72$ \\
Proteínas $(\mathbf{g} / \mathbf{k g})$ & $2,02 \pm 0,71$ & $1,86 \pm 0,60$ \\
Proteínas AVB (g/kg) & $1,09 \pm 0,52$ & $1,05 \pm 0,55$ \\
\hline
\end{tabular}

Kcal - quilocalorias; kcal/kg - quilocalorias por quilograma; g - gramas; AVB - alto valor biológico. ${ }^{* *} P \leq 0,01$.

Em relação às variáveis qualitativas, não houve diferenças significantes $(P>0,05)$ para classificação do índice de massa corporal, dobra cutânea tricipital e nível de atividade 
física e classe socioeconômica. Houve diferença significante para classificação a socioeconômica $(P \leq 0,01)$ (FIGURAS $6,7,8,9,10)$.

No índice de massa corporal, os voluntários da escola particular e pública apresentaram maiores percentuais dentro do normal, sendo $80 \%$ e $70 \%$ respectivamente. A ocorrência de baixo peso foi de $6 \%$ na escola particular e $2 \%$ na escola pública. Quando observados o sobrepeso e obesidade foram encontrados $22 \%$ na escola particular e $18 \%$ na escola pública. A obesidade foi encontrada somente na escola particular, sendo $2 \%$. Para as análises da dobra cutânea tricipital, foram observados que $30 \%$ dos voluntários da escola particular apresentaram valores aumentados e $28 \%$ dos voluntários da escola pública também apresentaram valores aumentados para medida da dobra cutânea tricipital.

Na classificação socioeconômica, houve uma concentração das voluntárias nas classes $\mathrm{A}^{1} \mathrm{a}$ $\mathrm{B}^{2}$ na escola particular e $\mathrm{B}^{1}$ a $\mathrm{C}^{2}$ na escola pública.

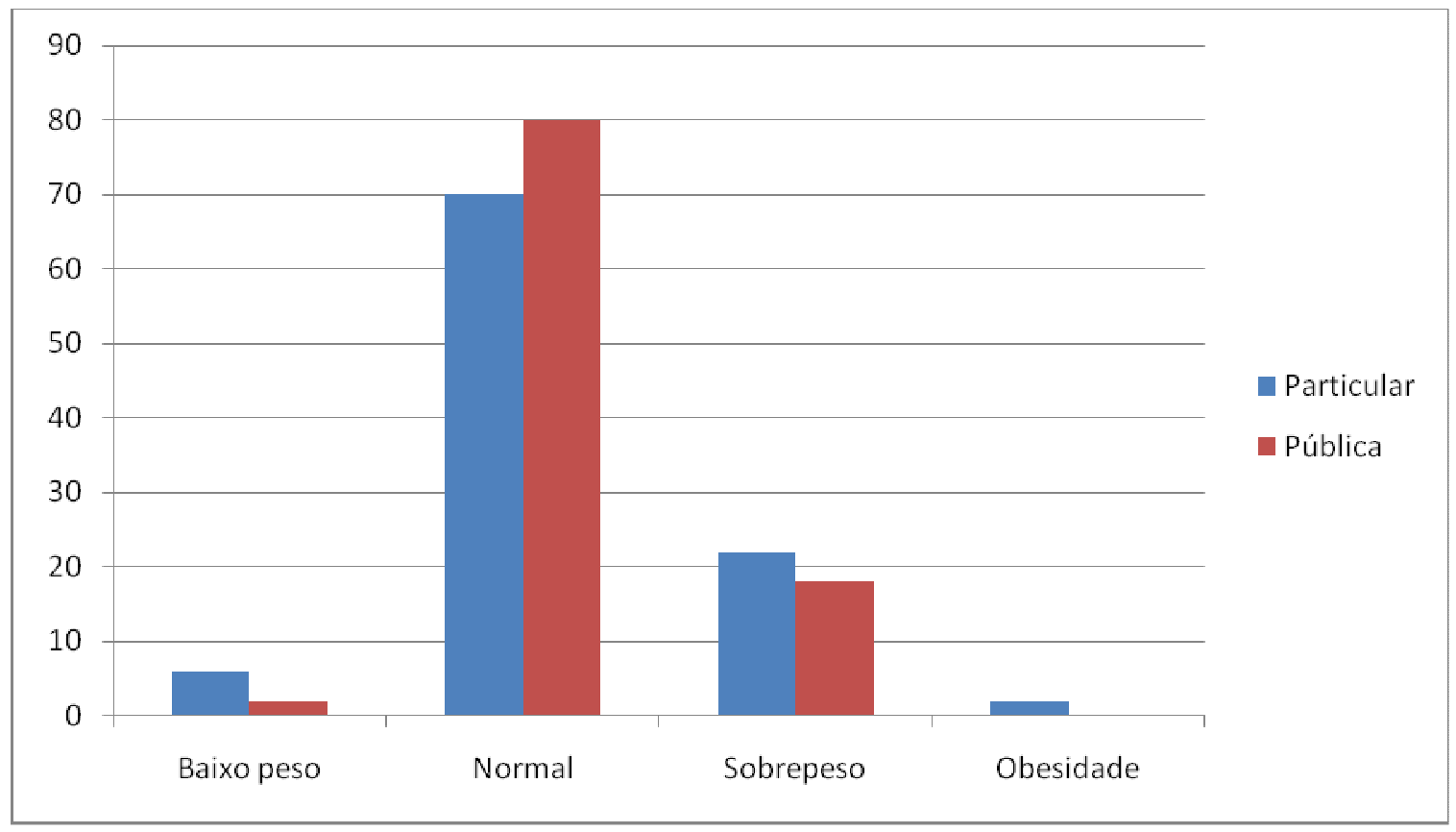

Figura 5: Distribuição percentual dos escolares do sexo masculino segundo a natureza da escola e a classificação do índice de massa corporal. $\mathrm{X}^{2}=1,52 ; P=0,47$. 


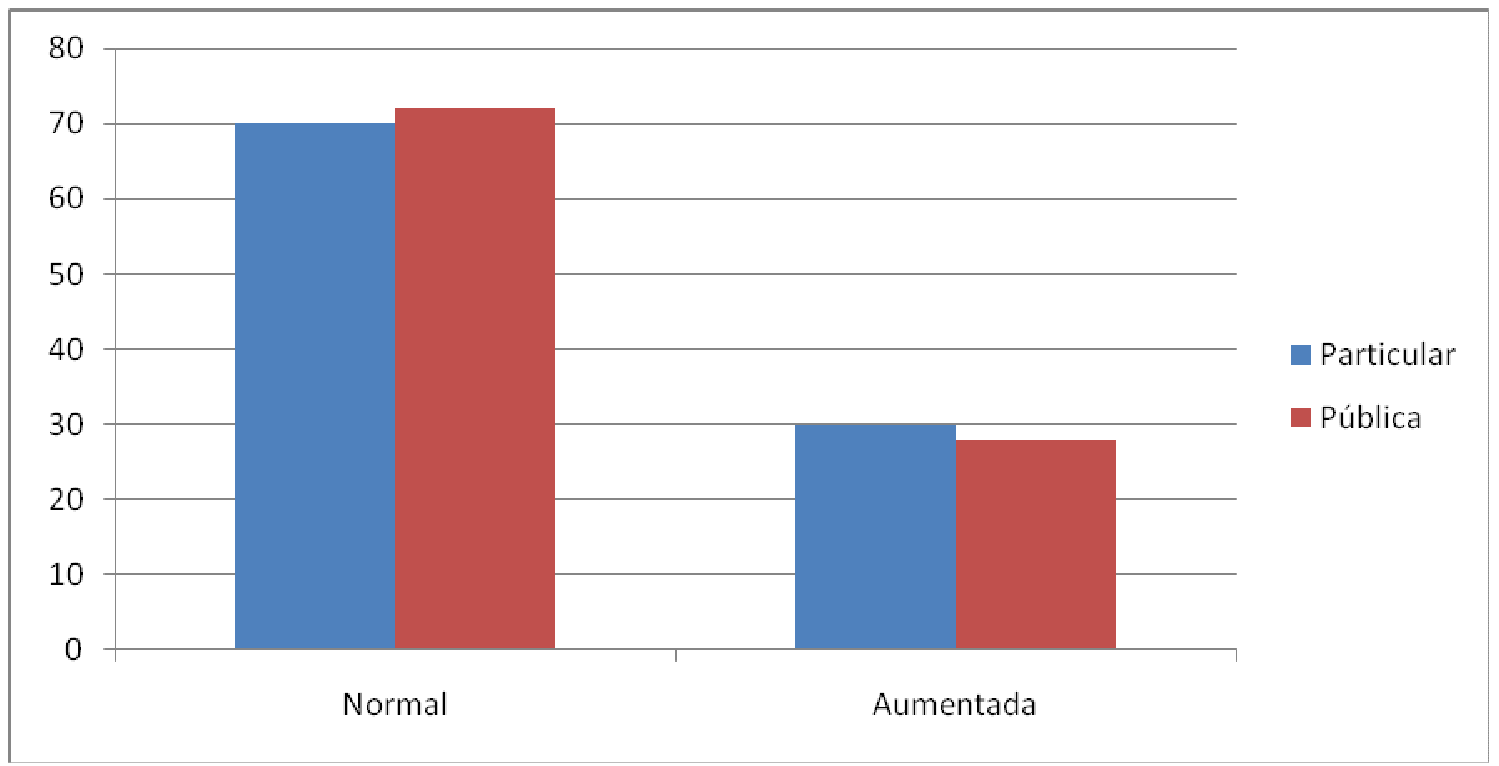

Figura 6: Distribuição percentual dos escolares do sexo masculino segundo a natureza da escola e a classificação da dobra cutânea tricipital. $\mathrm{X}^{2}=11,76 ; P \leq 0,001$.

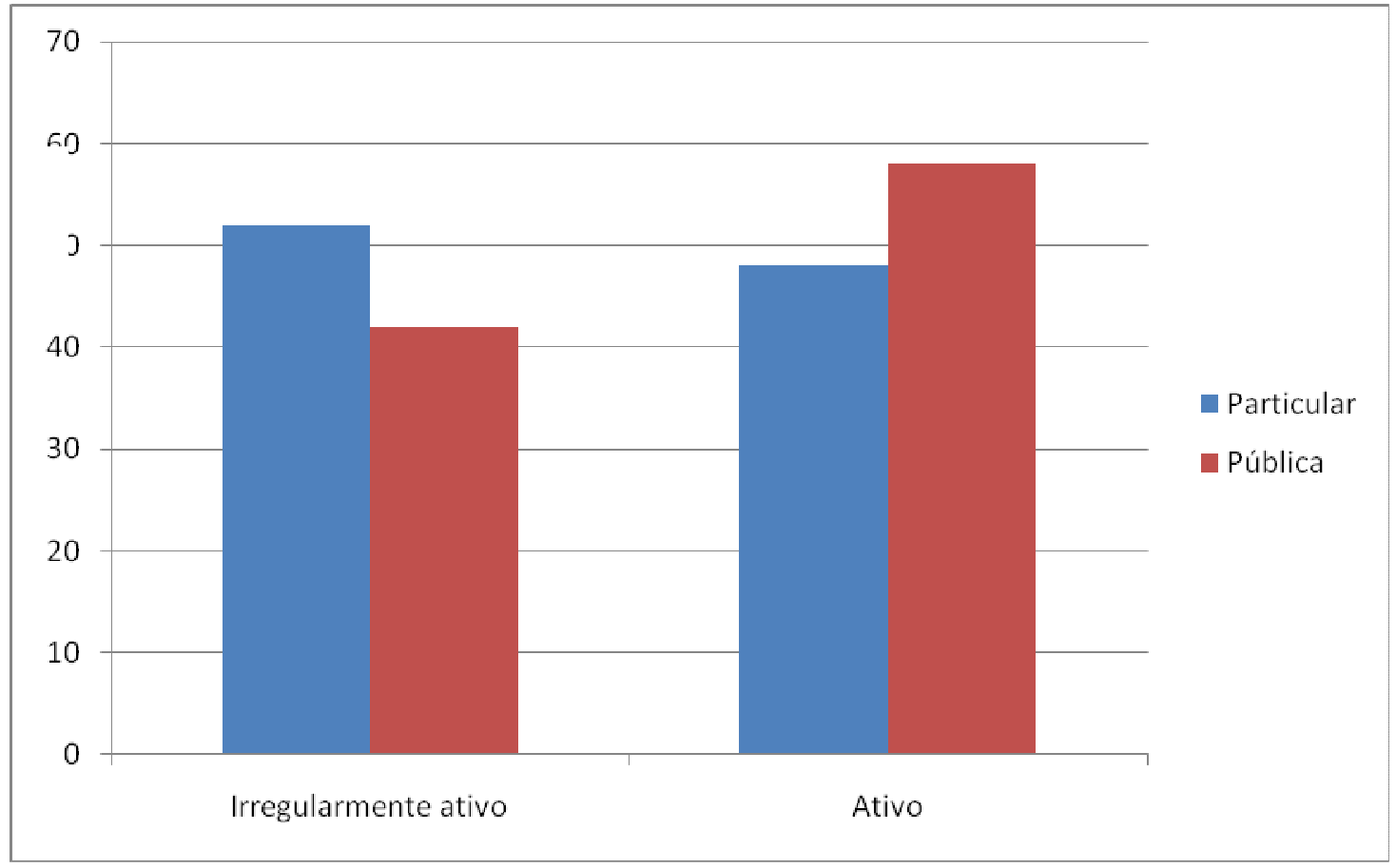

Figura 7: Distribuição percentual dos escolares do sexo masculino segundo a natureza da escola e a classificação do nível de atividade física. $\mathrm{X}^{2}=1,44 ; P=0,23$. 


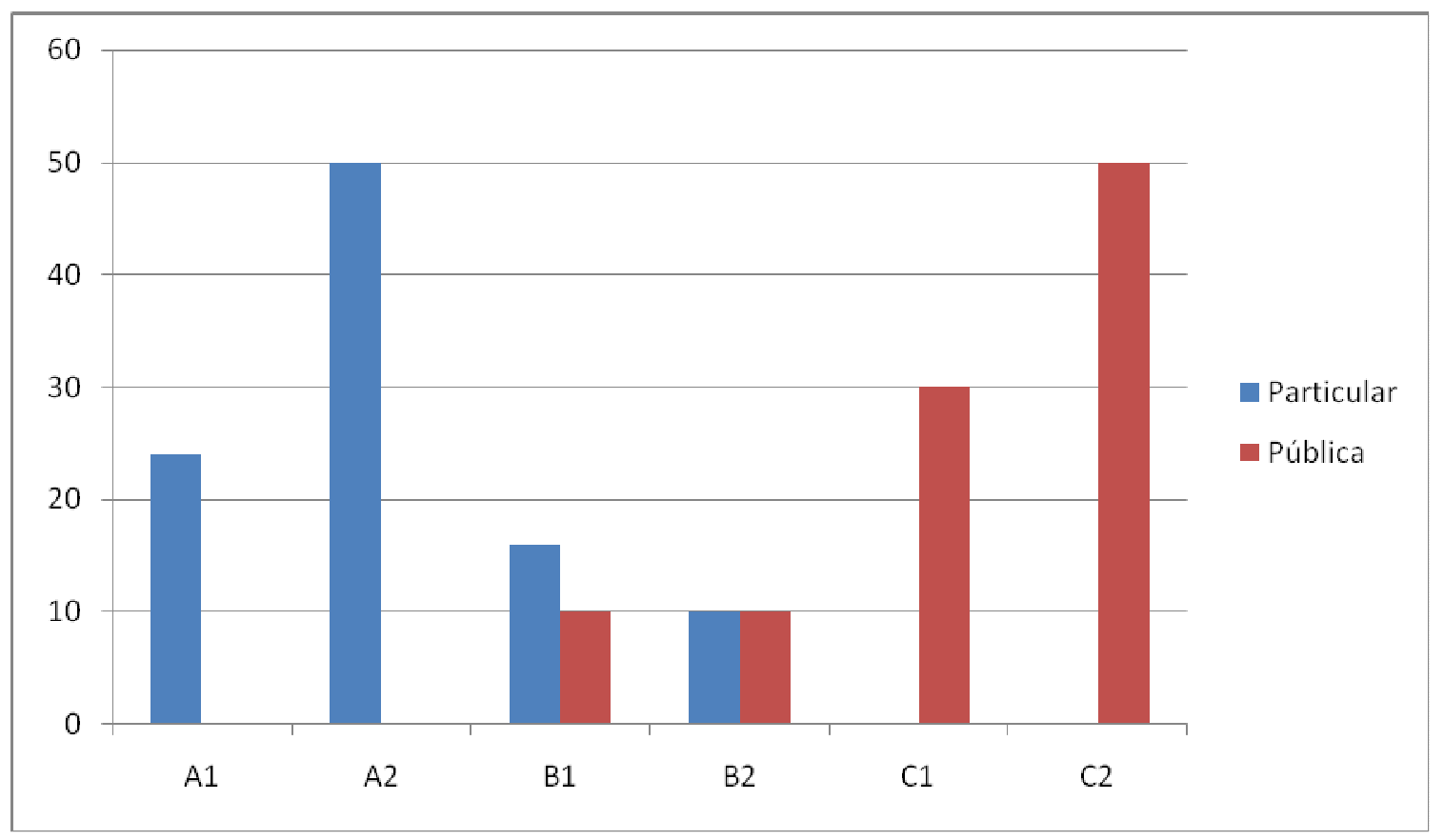

Figura 8: Distribuição percentual dos escolares do sexo masculino segundo a natureza da escola e a classificação socieconômica. $\mathrm{X}^{2}=79,91 ; P \leq 0,01$.

\section{DISCUSSÃO}

Modificações nos hábitos alimentares atrelados ao estilo de vida sedentário, presentes na sociedade moderna, são cruciais para o desenvolvimento da obesidade..$^{9,31-32}$

A obesidade é um problema que acomete diversas populações independente da fase de vida ou condição social. ${ }^{32}$ Existe grande preocupação com o aumento da prevalência da obesidade infanto-juvenil, que atinge grande parcela de crianças e adolescentes. ${ }^{29-33}$ Ressalta-se que quanto mais cedo o surgimento da obesidade, maiores o risco de patologias associadas, como exemplo a síndrome metabólica. ${ }^{32,34}$

Estudos indicam que em algumas cidades brasileiras o sobrepeso e obesidade atingiram patamares a $20 \%$, dado que preocupa e pode causar grande impacto nas hospitalizações e custos com saúde pública., ${ }^{9,31-32}$

Nessa direção, justifica-se a importância de investimentos na atenção primária da saúde, ou seja, se torna crucial medidas preventivas no intuito de minimizar quadros de obesidade infanto- juvenil. $^{19}$ 
Nesse contexto a escola é um importante espaço para a promoção da saúde, onde a intenção é cultivar hábitos de vida saudáveis dentre eles, prática de exercícios físicos e alimentação adequada. ${ }^{19} \mathrm{O}$ professor de educação física é um profissional com condições de desenvolver trabalhos na área de prevenção e promoção da saúde dentro do ambiente escolar, o que valoriza sua atuação na educação e formação dos alunos.

Diante desses fatos, o presente estudo investigou a composição corporal, nível da atividade física e hábitos alimentares de adolescentes do ensino médio, regularmente matriculados em uma escola da rede pública e uma da rede particular de ensino.

Nos adolescentes do gênero feminino e masculino não houve diferença na idade das escolas particular e pública, evidenciando a homogeneidade da amostra.

Nas duas escolas, os estudantes do sexo feminino e masculino referiram não apresentar doenças crônicas como diabetes e hipertensão arterial, o que era esperado, pois a prevalência destas doenças nesta faixa etária é muito baixa. ${ }^{20}$

$\mathrm{Na}$ análise socioeconômica, os alunos da rede particular apresentaram diferenças significantes quando comparados com os alunos da rede pública de ensino, com maior percentual de indivíduos nas classes socioeconômicas mais altas nos alunos da escola particular, nos adolescentes do sexo feminino e masculino.

$\mathrm{Na}$ discussão do presente estudo, os escolares foram separados por gênero, pois vale destacar que as adolescentes do sexo feminino quando comparadas com os do sexo masculino possuem marcantes diferenças de desenvolvimento da composição corporal e maturação sexual, ou seja, os desfechos que os resultados podem trazer são diferentes entre os gêneros. ${ }^{31,35}$

Quando verificadas as condições de excesso ponderal de gordura, as alunas do sexo feminino da escola pública apresentaram sobrepeso e obesidade de $40 \%$, sendo que $24 \%$ apresentaram valores de dobra cutânea aumentados. Tassitano et al., ${ }^{29}$ em estudo em escolares no Pernambuco, encontraram valores de sobrepeso e obesidade abaixo aos encontrados nesse estudo, sendo 13,9\%, o que pode ser justificado pelas condições Conexões: revista da Faculdade de Educação Física da UNICAMP, Campinas, v. 11, n. 2, p. 31-59, abr./jun. 2013.46 ISSN: 1983-9030 
socioeconômicas e fatores culturais. Os mesmos autores ainda destacaram que morar na zona urbana é fator de risco tanto para sobrepeso e obesidade em escolares, fato não estudado e verificado na presente pesquisa, pois as duas escolas estudadas localizam-se na zona urbana.

Em outro estudo, realizado na região Sul, foram encontrados $26,3 \%$ de sobrepeso e obesidade em adolescentes o que demonstra que as diferenças regionais também são determinantes nas questões de sobrepeso e obesidade. ${ }^{36}$ Pode-se destacar que o sobrepeso e a obesidade distribuem-se de forma diferente nas diversas regiões brasileiras, sendo que a região Nordeste é observada valores modestos de prevalência para ambas as situações, na região Sul e Sudeste, os valores de prevalência obtidos com sobrepeso e obesidade são próximos dos valores encontrados em países americanos. ${ }^{31,36-37}$

O que poderia justificar os altos valores de sobrepeso e obesidade nas alunas da escola pública é justamente o fato da transição epidemiológica estar ocorrendo em países em desenvolvimento como o Brasil, demonstrando que as taxas para o sobrepeso e obesidade estão crescendo em todos os extratos socioeconômicos. ${ }^{38}$

Quando analisada a escola particular as alunas do gênero feminino apresentaram menores valores menores de índice de massa corporal e dobra cutânea tricipital quando comparadas com as alunas da escola pública. Sendo que as alunas da escola particular apresentaram $12 \%$ de sobrepeso não apresentando obesidade e ainda, não obtiveram valores de dobra cutânea aumentada. Vale ressaltar que $68 \%$ das alunas da escola particular estavam dentro da normalidade.

O fato das alunas da escola particular terem apresentado percentual de sobrepeso baixo diverge de estudo realizado na cidade de Santos, os resultados encontrados nas voluntárias da escola particular, foram $22,2 \%$ e 20,3 para sobrepeso e obesidade respectivamente. ${ }^{38}$

Pode-se observar que as alunas da escola particular obtiveram melhores resultados de composição corporal quando comparadas com as alunas da rede pública, o que reforça a idéia que o sobrepeso e a obesidade estão atingindo classes mais baixas, e não somente classes mais elevadas. ${ }^{31,36-39}$

Conexões: revista da Faculdade de Educação Física da UNICAMP, Campinas, v. 11, n. 2, p. 31-59, abr./jun. 2013. 
Em relação à ingestão energética total, não ocorreram diferenças significantes, e em ambas as escolas foram observados valores de ingestão energética próximo do recomendado para o gênero e a idade, de $2200 \mathrm{kcal} / \mathrm{dia}$ ou $40 \mathrm{kcal} / \mathrm{kg} / \mathrm{dia} .{ }^{33}$ Entretanto, foram observadas diferenças significantes no consumo dos macronutrientes carboidratos e proteínas (TABELA 2) embora nas duas escolas as alunas ingeriram mais proteínas do que o recomendado para o gênero que é $0,8 \mathrm{~g} / \mathrm{Kg},{ }^{33}$ na escola pública as alunas ingeriam mais proteínas e menos carboidratos que na escola privada.

O nível socioeconômico, com maior percentual de alunas nas classes mais altas na escola particular que na pública, pode ter influenciado nos hábitos alimentares.

Em estudo realizado no Rio de Janeiro, os resultados indicaram que os adolescentes obesos ingeriam quantidades elevadas de gordura total quando comparados com adolescentes normais, fato que pode justificar a relação positiva que o excesso de gordura tem com a obesidade. $^{35}$

Faz-se necessário o controle alimentar dos adolescentes, pois o desequilíbrio alimentar é considerado um dos fatores ambientais que contribuem para o sobrepeso e obesidade ${ }^{33}$. É importante destacar que o comportamento alimentar é crucial para a prevenção de sobrepeso e obesidade. Dessa forma, trabalhos de conscientização, controle e reeducação alimentar são fundamentais em escolares. ${ }^{9,33,39-43}$

Quando avaliados os níveis de atividade física, os resultados foram semelhantes, o que indica que a prática de exercícios físicos parece não ser o responsável direto pelas diferenças antropométricas observadas. Porém, outros estudos sugerem que os níveis de atividade física parecem influenciar nas questões de aumento de sobrepeso e obesidade, ou seja, o sedentarismo deve ser combatido com campanhas eficazes de saúde preventiva, e dentro de foco o exercício físico se torna crucial. ${ }^{9,33,39-44}$

Ressalta-se que apesar de não haver diferenças significantes entre os níveis de atividade física, houve um grande percentual das voluntárias do sexo feminino irregularmente ativas. Fato esse preocupante e nesse aspecto, aumento da aderência exercícios físicos devem ser preconizas a fim de diminuir essa cultura sedentária. ${ }^{36,44-46}$

Conexões: revista da Faculdade de Educação Física da UNICAMP, Campinas, v. 11, n. 2, p. 31-59, abr./jun. 2013.48 ISSN: 1983-9030 
Diante das considerações programas de saúde pública e atendimentos primários devem ser recomendados em adolescentes no intuito de minimizar quadros de sobrepeso e obesidade, uma vez que as consequiências patológicas nesse público são evidentes e podem persistir na vida adulta. ${ }^{32,40,46,47,48,49,50}$

Nas análises dos adolescentes do sexo masculino, quando verificadas as condições de excesso ponderal de gordura, os alunos da escola pública apresentaram sobrepeso e obesidade de $18 \%$, sendo que $28 \%$ apresentaram valores de dobra cutânea aumentados. Tassitano et al., ${ }^{29}$ em estudo em escolares no Pernambuco, encontraram valores de sobrepeso e obesidade abaixo aos encontrados nesse estudo sendo 13,9\%, porém, indicando que os riscos de sobrepeso e obesidade também é evidenciado nos escolares do sexo masculino.

Quando observados os resultados para os alunos da escola particular os resultados encontrados para sobrepeso e obesidade foram de $24 \%$, sendo que $30 \%$ desses alunos apresentaram valores de dobra cutânea aumentados. Outros estudos também encontraram valores próximos ao achado na presente pesquisa quando avaliado sobrepeso e obesidade. $9,32,39,40-48$

Os alunos não apresentaram diferenças significantes quando foram observadas as variáveis quantitativas como idade, massa corporal, estatura, índice de massa corporal, percentual de gordura e ingestão de carboidratos. Essa informação é divergente quanto comparado com estudo que encontrou diferenças nessas variáveis. ${ }^{46}$ Em escolares da cidade de Santos as variáveis analisadas também foram divergentes dos resultados encontrados na presente pesquisa, porém, as taxas de sobrepeso e obesidade foram de $22,2 \%$, aproximando os resultados encontrados no presente estudo. ${ }^{38,50}$

Quando analisados os inquéritos alimentares dos alunos do gênero masculino, os mesmo apresentaram diferenças significantes apenas para a quantidade de energia total (TABELA 4), as outras variáveis não foram observadas diferenças significantes. Porém, destaca-se que o consumo de proteínas também foi elevado tanto nos voluntários da rede pública quanto na rede particular. 
A composição corporal semelhante nos alunos das escolas pública e particular pode ser atribuída à dieta alimentar, que foi similar nos voluntários apesar dos alunos da rede particular apresentar maiores valores de ingestão energética total, não houve diferença significante quando a energia foi expressa em $\mathrm{kcal} / \mathrm{kg}$, e em ambas as escolas a ingestão calórica total foi menor que as recomendações para gênero e idade. ${ }^{33}$ Os voluntários das duas escolas apresentaram uma dieta abaixo do recomendado que é de $3000 \mathrm{kcal} / \mathrm{dia}$ ou 45 $\mathrm{kcal} / \mathrm{kg} / \mathrm{dia}$, ou seja, faz-se necessário maior controle alimentar dos adolescentes a fim de evitar problemas atrelados a aspectos nutricionais. ${ }^{33}$

O controle alimentar dos adolescentes é crucial, pois o desequilíbrio alimentar é considerado um dos fatores ambientais que contribuem para o sobrepeso e obesidade. ${ }^{33,49}$

De acordo com Rodrigues et al., ${ }^{46}$ os hábitos com relação a merenda dos escolares merecem atenção, pois pode- se notar que há desequilíbrio na alimentação de escolares, de forma a melhorar e garantir as demandas nutricionais dos mesmos.

Destaca-se que a quantidade de gordura dos alunos das duas escolas estava próximo do recomendado, não tendo relação direta com sobrepeso e obesidade divergindo de estudo realizado no Rio de Janeiro, os resultados indicaram que os adolescentes obesos ingeriam quantidades elevadas de gordura total quando comparados com adolescentes normais, fato que pode justificar a relação positiva que o excesso de gordura tem com a obesidade. ${ }^{35,50}$

O presente estudo utiliza técnicas de medidas antropométricas e questionários previamente validados, mas apresenta resultados que analisados de um ponto de vista estritamente técnico podem parecer contraditórios, como a prevalência de excesso de peso corporal nos adolescentes do sexo masculino que tem ingestão energética média abaixo do recomendado. Esses dados parecem ser explicados pela baixa prática de exercícios físicos, e apontam a necessidade de serem investigados diversos fatores pelos profissionais de saúde que trabalham nas escolas. Pois, apesar de cerca de $80 \%$ dos alunos da escola pública e $70 \%$ dos alunos da escola particular não apresentarem sobrepeso ou obesidade pelo índice de massa corporal, cerca de metade dos alunos da amostra total eram irregularmente ativos. Provavelmente, a prevalência de excesso de peso corporal não foi maior nestes alunos pouco ativos porque a ingestão de energia foi abaixo do recomendado. Conexões: revista da Faculdade de Educação Física da UNICAMP, Campinas, v. 11, n. 2, p. 31-59, abr./jun. 2013.50 ISSN: 1983-9030 
O nível socioeconômico, com maior percentual de alunos nas classes mais altas na escola particular que na pública, parece não ter influenciado nos hábitos alimentares e da prática de atividades físicas.

Pode-se concluir que a composição corporal dos escolares do sexo masculino das escolas pública e privado foi semelhante porque a dieta alimentar e a prática de atividade física foram similares nas duas escolas. Por outro lado, nos escolares do sexo feminino houve diferenças significantes na composição corporal nas duas escolas que podem ser explicadas pela dieta alimentar, pois a prática de atividades físicas foi similar.

Destaca-se que vários estudos indicaram que a inatividade física associados a outros fatores como alimentação irregular podem desencadear sobrepeso e obesidade. $9,32,33,39,40,41,42,43,44,46,47,48$

Estudos investigando a prática de atividade física e diferentes locais do Brasil são muito relevantes, pois existem muitas diferenças regionais. Em estudo de meta-análise, Barufaldi et al., ${ }^{46}$ observaram taxas de prevalência de inatividade física que variaram de $14 \%$ a $91 \%$ para o sexo feminino e $2 \%$ a $80 \%$ para o masculino, na maioria dos estudos com maior prevalência de inatividade física nas mulheres, sendo que as menores taxas de prevalência foram na Região Sul, e as maiores nas regiões Norte e Nordeste. Os valores encontrados neste estudo, cerca de $50 \%$ em homens e mulheres, reforçam a importância de estudo em diferentes regiões do país, pois as variações são muito grandes.

Diante dos fatos em escolares do gênero feminino e masculino na escola da rede pública e rede particular, se torna evidente que atitudes em relação à promoção prática de exercícios físicos e hábitos alimentares são fundamentais. A proporção de adolescentes com sobrepeso e obesidade condiz com resultados encontrados na literatura. 9,32,39-48,50

A valorização, estímulo à prática de atividade física e cultural de hábitos alimentares são de grande utilidade na saúde dos escolares tanto na rede pública quanto na rede particular. $^{44}$ 
Trabalhos voltados em saúde pública são cada vez mais observados e devem ser recomendados para adolescentes. ${ }^{32,48-49}$ Nesse aspecto, incentivos e campanhas de saúde pública compreendendo ações de reeducação alimentar e aumento à atividade física no âmbito escolar, de forma continuada, deve promover mudanças no estilo de vida de forma a melhorar condições de saúde e qualidade de vida. ${ }^{6,7,32,34,43}$

Os investimentos e campanhas em saúde pública e atendimentos primários no ambiente escolar parecem ser estratégias eficientes no controle e diminuição de sobrepeso e obesidade em escolares adolescentes tanto na rede pública quanto na rede particular de ensino.

A implantação de programas que atendam a demanda nutricional, a fim de melhorar a saúde e qualidade de vida dos adolescentes pode ser ferramenta de suma importância na prevenção de sobrepeso e obesidade. Dessa forma, prejuízos à saúde poderão ser evitados na adolescência e futuramente na fase adulta.

Há necessidade de acontecer mais estudos nessa linha de pesquisa, uma vez, que os diversos estudos que se propuseram estudar escolares adolescentes divergiram nos resultados encontrados. Fatos esses que podem ser justificados vários protocolos utilizados, além das diferenças culturais, socioeconômicas e demográficas.

\section{CONCLUSÃO}

Os resultados obtidos, em relação aos escolares do sexo feminino, permitem concluir que:

A avaliação antropométrica indicou uma melhor composição corporal das alunas da escola particular que da pública, com menores valores de índice de massa corporal e dobra cutânea tricipital. A ingestão energética das alunas foi semelhante nas duas escolas, mas a ingestão de proteínas foi menor e de carboidratos maior nas alunas da escola pública;

O nível de atividade física foi semelhante nas alunas das duas escolas, de modo que não dever ter proporcionado as diferenças de composição corporal, mas a prevalência de inatividade física foi alta nas duas escolas; 
O nível socioeconômico evidenciou maior percentual de alunas nas classes mais altas na escola particular que na pública, o que pode ter influenciado nos hábitos alimentares.

Em relação aos escolares do sexo masculino, conclui-se:

A avaliação antropométrica indicou uma composição corporal semelhante nas duas escolas, o que pode ser atribuído a dieta alimentar e o nível de atividade física, que também foram semelhantes nos alunos das escolas particulares e públicas. A prevalência de inatividade física também foi alta nas duas escolas;

O nível socioeconômico evidenciou maior percentual de alunos nas classes mais altas na escola particular que na pública, mas parece não ter influenciado nos hábitos alimentares e da prática de atividades físicas;

Os hábitos e recomendações da prática de exercícios físicos devem ser ressaltados uma vez que a pesquisa apresentou grandes porcentagens em relação à inatividade física. O professor de educação física se torna fundamental nesse processo e dentro do ambiente escolar, ele tem a função e estimular e promover práticas saudáveis dos alunos, uma vez que o sobrepeso e obesidade são crescentes em escolares. Nesse aspecto, o professor de educação física é um importante agente para promoção da saúde.

\section{REFERÊNCIAS}

${ }^{1}$ MOREIRA, W. W; SIMÕES, R; MARTINS, I. C. Aulas de educação física no ensino médio. Campinas: Papirus, 2010.

\section{${ }^{2}$ NAHAS, M. V. Atividade física, saúde e qualidade de vida: conceitos e sugestões para um estilo de vida mais ativo.Londrina: Midiograf, 2001.}

${ }^{3}$ NIEMAN, D. Exercício e saúde. São Paulo: Manole, 1999.

Conexões: revista da Faculdade de Educação Física da UNICAMP, Campinas, v. 11, n. 2, p. 31-59, abr./jun. 2013.53 ISSN: 1983-9030 
${ }^{4}$ NAHAS, M. V. Obesidade: controle de peso e atividade física. Londrina: Midiograf, 1999.

${ }^{5}$ MONTEIRO, A. G. Emagrecimento: exercício e nutrição. Londrina: Midiograf, 2007.

${ }^{6}$ AMARAL, A. P. A.; PALMA, A. P. Perfil epidemiológico da obesidade em crianças: relação entre televisão, atividade física e obesidade. Revista Brasileira de Ciência e Movimento, Brasília, v. 4, p.19-24, 2001.

${ }^{7}$ SABIA, R. V.; SANTOS, J. E.; RIBEIRO, R. P. P. Efeito da atividade física associada à orientação alimentar em adolescentes obesos: comparação entre o exercício aeróbio e anaeróbio. Revista Brasileira de Medicina do Esporte, São Paulo, v.10, n. 5, p. 349-355, 2004.

${ }^{8}$ INSTITUTO BRASILEIRO DE GEOGRAFIA E ESTATÍSITICA (IBGE). Pesquisa de orçamentos familiares 2002-2003: antropometria e análise do estado nutricional de crianças adolescentes no Brasil. Disponível em: <http://www.ibge.gov.br/home/estatistica/populacao/condicaodevida/pof/2003medidas/co mentario.pdf>. Acesso em: 20 set. 20011.

${ }^{9}$ OLIVEIRA, C .L. et al. Obesidade e síndrome metabólica na infância e adolescência. Revista de Nutrição, Campinas, v.17, n. 2, 2004.

${ }^{10}$ ESCRIVÃO, M. A. M. S. et al. Obesidade exógena na infância e adolescência. Journal of Pediatrics, Saint Louis, v. 76, supl. 3, p. 305-310, 2000.

${ }^{11}$ EBBELING, C. B.; PAWLAK, D. B.; LUDWIG, D. S. Childhood obesity: public-health crisis, common sense cure. Lancet, London, v. 360, p. 473-482, 2002.

${ }^{12}$ BRASIL. Ministério da Saúde. Portaria n.154, de 24 de janeiro de 2008: cria os Núcleos de Apoio á Saúde da Família (NASF). Diário Oficial da União, Brasília, 4 mar. 2008. Seção I. p. 38-42.

Conexões: revista da Faculdade de Educação Física da UNICAMP, Campinas, v. 11, n. 2, p. 31-59, abr./jun. 2013. ISSN: 1983-9030 
${ }^{13}$ BRASIL. Ministério da Saúde. Secretaria de Atenção da Saúde. Caderno de atenção básica: obesidade. Brasília, 2009.

${ }^{14}$ TOLOCKA, R. E. et al.. Perfil de crescimento e estado nutricional em crianças de creches e pré- escolas do município de Piracicaba. Revista da Educação Física/UEM, Maringá, v.19, n.3, p. 343-351, 2008.

${ }^{15}$ SOCIEDADE BRASILEIRA DE PEDIATRIA. Departamento de Nutrologia. Obesidade na infância e na adolescência: manual de orientação. São Paulo, 2008.

${ }^{16}$ GODOY, M. I Consenso Nacional de Reabilitação Cardiovascular: (fase crônica) Arquivos Brasileiros de Cardiologia, São Paulo, v. 69, n. 4, p. 267-291, out. 1997.

${ }^{17}$ ABRANTES, M. M.; LAMOUNIER, J. A.; COLOSIMO, E. A. Prevalência de sobrepeso e obesidade em crianças e adolescentes das regiões Sudeste e Nordeste. Jornal de Pediatria, Rio de Janeiro, v.78. n. 4, 2002.

${ }^{18}$ SOCIEDADE BRASILEIRA DE CARDIOLOGIA. V Diretrizes Brasileiras de Hipertensão Arterial. Arquivos Brasileiros de Cardiologia, São Paulo, v. 89, n. 3, p. e24e79, 2010.

${ }^{19}$ SEABRA, A. F et al. Determinantes biológicos e sócio-culturais associados à prática de atividade física de adolescentes. Cadernos de Saúde Pública, Rio de Janeiro, v. 24, n. 4, p. 721-736, 2008.

${ }^{20}$ BARROS, M. B. A. et al. Desigualdades sociais na prevalência de doenças crônicas no Brasil, PNAD-2003. Ciência e Saúde Coletiva, v.11, n. 4, p. 911-926, 2006.

${ }^{21}$ PARDINI, R. et al. Validação do questionário internacional de nível de atividade física (IPAQ - versão 6): estudo piloto em adultos jovens brasileiros. Revista Brasileira de Ciência e Movimento, Brasília, v. 9, n. 3, p. 45-51, 2001. 
${ }^{22}$ VESPASIANO, B. S.; DIAS, R.; CORREA, D. A. A utilização do Questionário Internacional de Atividade Física (IPAQ) como ferramenta diagnóstica do nível de aptidão física: uma revisão no Brasil. Saúde em Revista, Piracicaba, v. 12, n. 32, p. 49-54, 2012.

${ }^{23}$ THOMPSON, F. E.; BYERS, T. Dietary assessment resource manual. Journal of Nutrition, Philadelphia, v.124, p. 224-231,1994.

${ }^{24}$ ASSOCIAÇÃO BRASILEIRA DE EMPRESAS DE PESQUISA (ABEP). Critério de Classificação Econômica Brasil (CCEB). Disponível em: <http://www.abep.org/codigosguias/CCEB2008-Base2006e2007.pdf>. Acesso em: 2 abr. 2011.

${ }^{25}$ COSTA, R. F. Composição corporal: teoria e prática da avaliação. Barueri: Manole, 2001 .

${ }^{26}$ COLE, T. J. et al. Establishing a standard definition for child overweigth and obesity worldwide: international survey. British Medical Journal, London, v. 320, p. 1240-1244, 2000.

${ }^{27}$ COLE, T. J. et al. Body mass index cuts offs to define thinnes in children and adolescents: international survey. British Medical Journal, London, v. 335, p. 194-201, 2007.

${ }^{28}$ FRISANCHO, A. R. New norms of upper limb fat and muscle áreas for assessment of nutritional status. American Journal of Clinical Nutrition, New York, v. 34, p. 2540$2545,1981$.

${ }^{29}$ TASSITANO, R.M. et al. Prevalência e fatores associados ao sobrepeso e à obesidade em adolescentes, estudantes de escolas de ensino médio de Pernambuco, Brasil. Cadernos de Saúde Pública, Rio de Janeiro, v. 25, n.12, p. 2639-2652, dez. 2009. 
${ }^{30}$ LEAL, V. S. et al. Excesso de peso em crianças e adolescentes no estado de Pernambuco, Brasil: prevalência e determinantes. Cadernos de Saúde Pública, Rio de Janeiro, v. 28, n. 6, 2012.

${ }^{31}$ MARCONDES, E. et al. Pediatria básica: pediatria geral e neonatal. 9. ed. São Paulo: Sarvier, 2003.

${ }^{32}$ TIENE, D. C. F.; VESPASIANO, B. S. Treinamento aeróbio: perspectivas sobre intensidades voltadas ao emagrecimento em adolescentes. Revista Brasileira de Obesidade, Nutrição e Emagrecimento, São Paulo, v. 6, n. 32, p.116-122, 2012.

${ }^{33}$ MAHAN, L. K; ESCOTT-STUMP, S. Karuse: alimentos, nutrição e dietoterapia. São Paulo: Roca, 2005.

${ }^{34}$ DUTRA, C. L; ARAÚJO, C. L; BERTOLDI, A. D. Prevalência de sobrepeso em adolescentes: um estudo de base populacional em uma cidade no Sul do Brasil. Cadernos de Saúde Pública, Rio de Janeiro, v. 22, n. 1, p. 151-162, jan. 2006.

${ }^{35}$ KUSCHNIR, M. C. C. et al. A saúde de adolescentes e jovens: competências e habilidades. Disponível em: $<$ http://portal.saude.gov.br/portal/arquivos/multimedia/adolescente/textos_comp/tc_06.htm 1>. Acesso em: 3 mar. 2010.

${ }^{36}$ COSTA, R. F.; CINTRA, I. P.; FISBERG, M. Prevalência de sobrepeso e obesidade em escolares da cidade de Santos, SP. Arquivos Brasileiros de Endocrinologia e Metabologia, São Paulo, v. 50, n.1, p. 60-67, 2006.

${ }^{37}$ STYNE, D. M. Childhood and adolescent obesity. Prevalence and significance. Pediatric Clinics of North America, Philadelphia, v. 48, p. 823-853, 2001.

${ }^{38}$ OLIVEIRA, C. L.; FISBERG, M. Obesidade na infância e adolescência uma verdadeira epidemia. Arquivos Brasileiros de Endocrinologia e Metabologia, São Paulo, v. 42, n. 2, p.107-108, 2003.

Conexões: revista da Faculdade de Educação Física da UNICAMP, Campinas, v. 11, n. 2, p. 31-59, abr./jun. 2013.57 ISSN: 1983-9030 
${ }^{39}$ GUEDES, D. P.; GUEDES, J. E. R. P. Controle do peso corporal: composição corporal, atividade física e nutrição. Rio de Janeiro: Shape; 2003.

${ }^{40}$ LIMA, S. C. V. C. et al. Perfil lipídico e peroxidação de lipídeos no plasma de crianças e adolescentes com sobrepeso e obesidade. Porto Alegre. Jornal de Pediatria, v. 80, n. 1, p. 23-28, jan./fev. 2004.

${ }^{41}$ ALVES, B. S. Obesidade na infância: critérios diagnósticos e impacto no rendimento escolar. 2007. Dissertação (Mestrado em Ciências Médicas) - Faculdade de Medicina. Universidade Federal do Rio Grande do Sul, Porto Alegre, 2007.

${ }^{42}$ TERRES, N. G. Prevalência e fatores associados ao sobrepeso e à obesidade em adolescentes. Revista de Saúde Pública, São Paulo, v. 40, n. 4, 2006.

${ }^{43}$ REZENDE, V. A. et al. Prevalência de sobrepeso e obesidade em alunos de uma escola da rede pública de Anápolis. Anuário da Produção de Iniciação Científica Discente, v.11, n.12, p. 203-213, 2008.

${ }^{44}$ RODRIGUES, P. A. et al. Prevalência e fatores associados a sobrepeso e obesidade em escolares da rede pública. Ciência e Saúde Coletiva, v.16, supl.1, p. 1581-1588, 2011.

${ }^{45}$ COSTA, C. D.; FERREIRA, M. G.; AMARAL, R. Obesidade infantil e juvenil. Acta Médica Portuguesa, Lisboa, v. 23, n.3, p. 379-384, 2010.

${ }^{46}$ BARUFALDI, L. A. et al. Meta-analysis of the prevalence of physical inactivity among Brazilian adolescents. Cadernos de Saúde Pública, Rio de Janeiro, v. 28, n. 6, jun. 2012.

${ }^{47}$ SANTOS, L. A. S. O fazer educação alimentar e nutricional: algumas contribuições para reflexão. Ciência \& Saúde Coletiva, Rio de Janeiro, v.17, n. 2, p. 453-462, 2012.

${ }^{48}$ ROSENBAUM, M.; LEIBEL, R. L. The physiology of body weight regulation: relevance to the etiology of obesity in children. Pediatrics, v.101,n.3, p. 525-539, 1998. 
${ }^{49}$ ABRAnTES, M. M.; LAMOUNIER, J. A.; COLOSIMO, E. A. Prevalência de sobrepeso e obesidade em crianças e adolescentes das regiões Sudeste e Nordeste. Jornal de Pediatria, Rio de Janeiro, v. 78. n. 4, 2002.

${ }^{50}$ BALABAN, G.; SILVA,G. A. P. Prevalência de sobrepeso em crianças e adolescentes de uma escola da rede privada de Recife. Jornal de Pediatria, Rio de Janeiro, v. 77, p. 96$100,2001$.

Recebido em: 01 abr. 2013 Aceito em: 12 jun. 2013

Contato: Bruno de Souza Vespasiano brunovespasiano@msn.com 